\title{
Modelling of DC/DC Boost Converter in Visual Programing Environments
}

\author{
Gergana Vacheva'), Nikolay Hinov ${ }^{1)}$, and Zoran Zlatev ${ }^{1)}$ \\ 1) Department of Power Electronics, \\ Technical University of Sofia, Sofia, Bulgaria, \\ gergana_vacheva@tu-sofia.bg
}

\begin{abstract}
The boost converter are the most commonly used DC/DC converters, especially for automotive applications, power amplifier applications, adaptive control applications, battery power systems, consumer electronics and communication applications. This is because the battery charge requires high $D C$ voltage to be fully charged. The main object of the research in the current paper is to examine the operation of the boost converter in visual programing environments like Matlab and LabVIEW. A mathematical model of the converter and its parameters are presented. The simulation results states that Matlab/Simulink is a suitable platform for control and regulation of the simulation processes, in additional to its dominant role in conducting research tasks. Similarly, LabVIEW software provides the possibility to be used for application that requires test, measurement and control with rapid access to hardware and data insights.
\end{abstract}

\section{INTRODUCTION}

There are several requirements for the necessity of examination to the mathematical model of the boost converter in different visual programming environments $[1-3]$. The basic problem is keeping the output voltage in the specified voltage interval. Here is presented the main difficulties:
- Changing of the properties of some of the components in the converter

- Changing of the converter topology

- Changing of the controller

- Increasing of the number of signals that are measured and used by the controller.

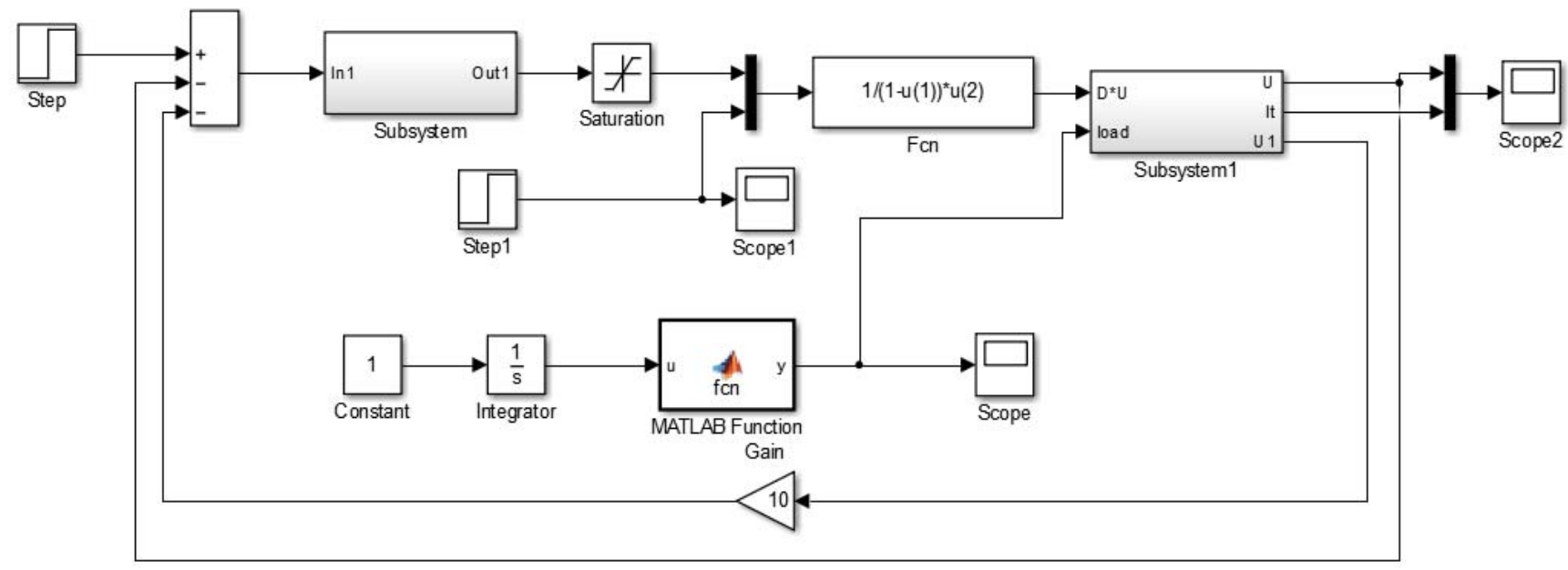

Fig. 1. Scheme of boost converter in LabVIEW 


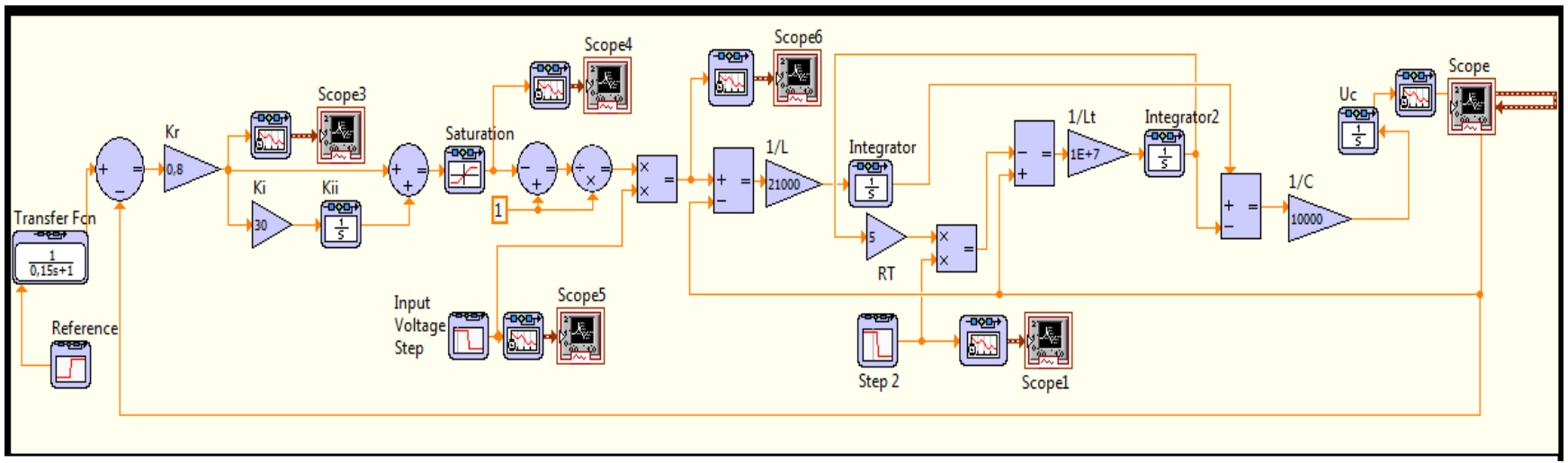

Fig. 2. Scheme of boost converter in LabVIEW

\section{MOdel OF BOOST CONVERTER}

At Fig. 1 is visualized the scheme of the examined boost converter with proportional-integral (PI) regulator in Matlab/Simulink. The parameters of the used controller are selected by means of ZieglerNichols method. For this research is used classical scheme of boost converter. In the current paper will be examined the process of the DC/DC converter also in LabVIEW at Fig. 2.

\subsection{Mathematical model}

The following system of differential equations describes the mathematical model of the boost converter:

$$
\begin{gathered}
L \frac{d i_{L}}{d t}+U_{C}=\frac{1}{1-D} U_{i} \\
i_{T} R_{T}+L_{T} \frac{d i_{T}}{d t}=U_{C} \\
i_{L}+i_{T}=C \frac{d U_{i}}{d t}
\end{gathered}
$$

Where $i_{L}$ is the current through the inductance $L, i_{T}$ is the current through the load $R T$ and $L T, U C$ is the voltage of the capacitor $C, D$ is the duty cycle.

The used variables and their values are presented in Table 1.

\begin{tabular}{cc}
\hline \hline Variables (Indication) & Values \\
\hline Capacitor $(\mathrm{C})$ & $100^{*} 10^{-6}[\mathrm{~F}]$ \\
\hline Inductance $(\mathrm{L})$ & $47^{*} 10^{-6}[\mathrm{~F}]$ \\
\hline$(\mathrm{Lt})$ & $0.1^{*} 10^{-6}[\mathrm{~F}]$ \\
\hline Load $(\mathrm{RT})$ & $5[\Omega]$ \\
\hline Input voltage & $12[\mathrm{~V}]$ \\
\hline $\begin{array}{c}\text { Proportional coefficient } \\
(\mathrm{kr})\end{array}$ & 0.8 \\
\hline Integral coefficient $(\mathrm{ki})$ & 30 \\
\hline
\end{tabular}

\section{RESULTS}

The obtained results are simulated in Matlab/Simulink and in LabVIEW and presented on Fig. 3 to Fig. 7 respectively.

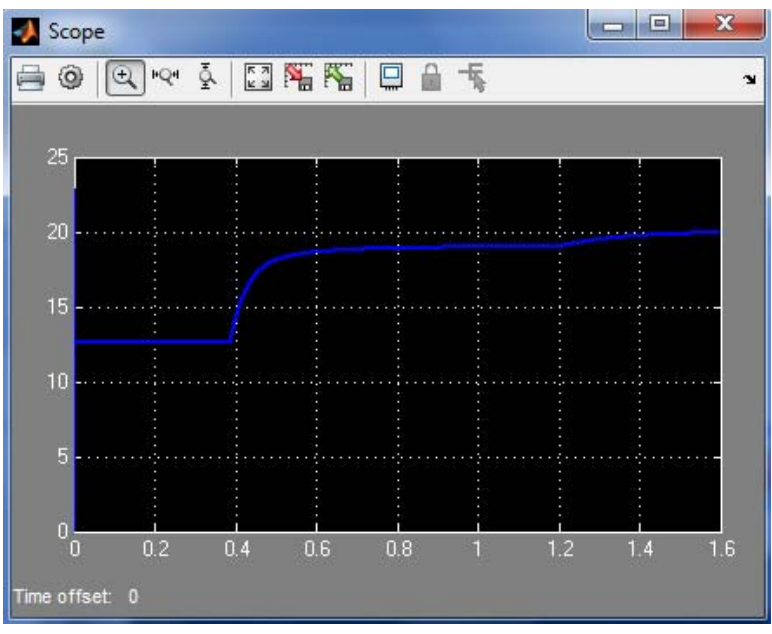

Fig. 3. The output voltage in Matlab/Simulink 


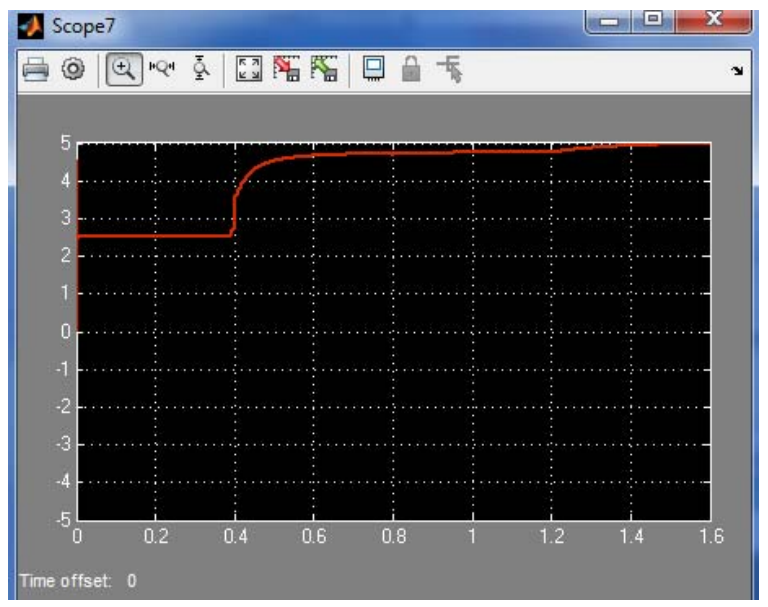

Fig. 4. Load current in Matlab/Simulink

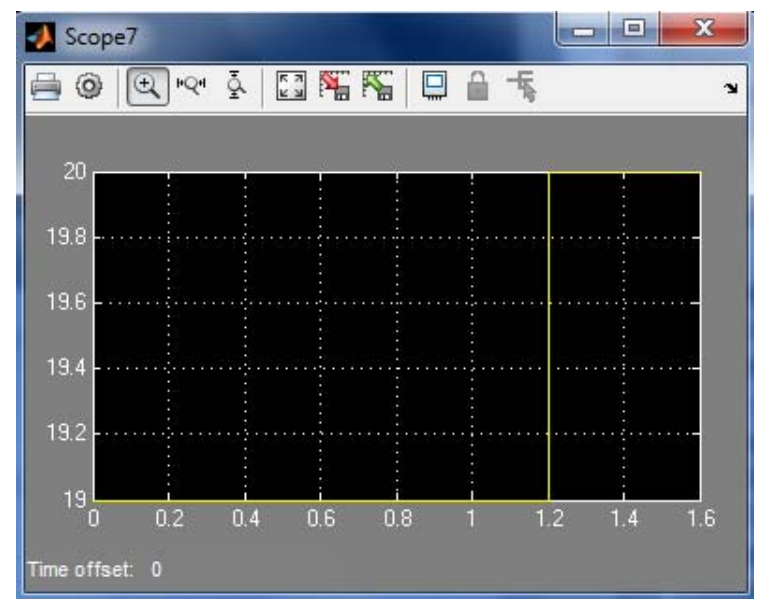

Fig. 5. Changing of the reference from $19 \mathrm{~V}$ to $20 \mathrm{~V}$

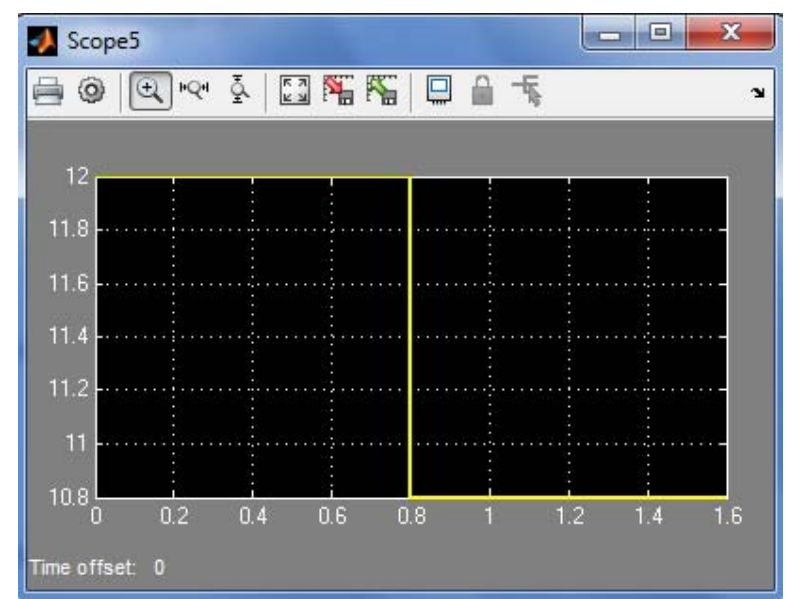

Fig. 6. Changing of the input voltage

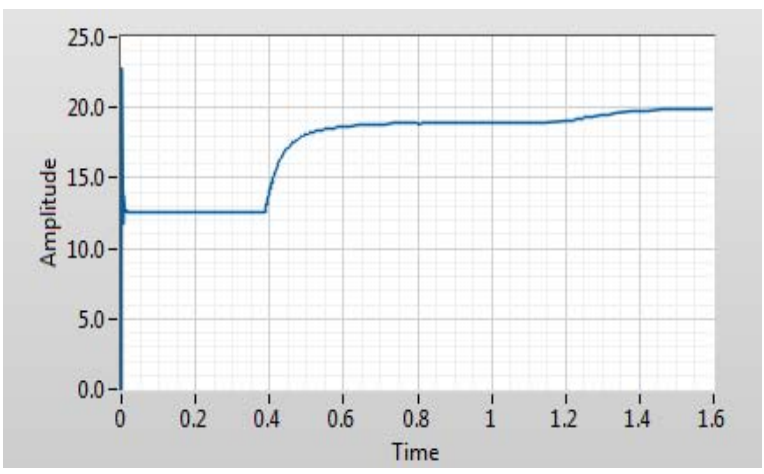

Fig. 7. Output voltage in LabVIEW

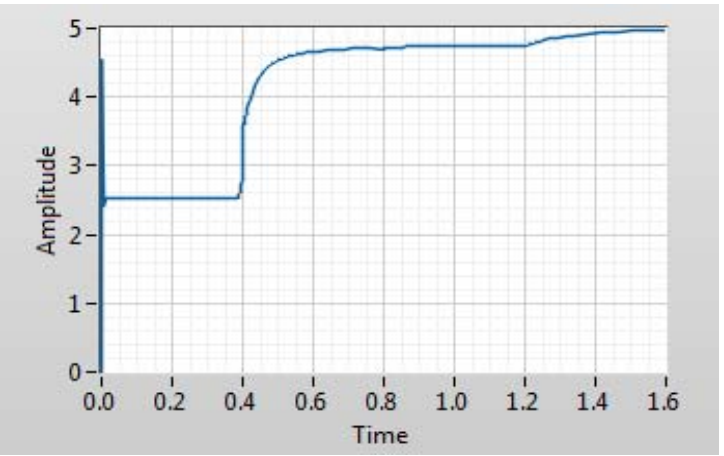

Fig. 8. Load current in LabVIEW

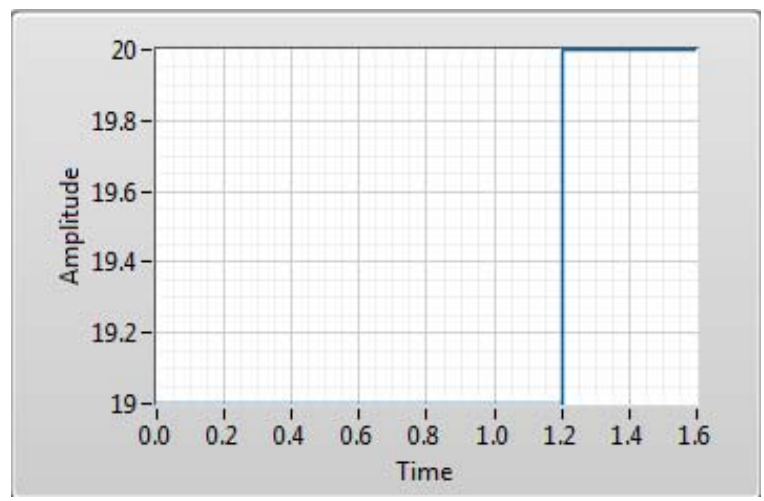

Fig. 9. Changing of the reference from $19 \mathrm{~V}$ to $20 \mathrm{~V}$

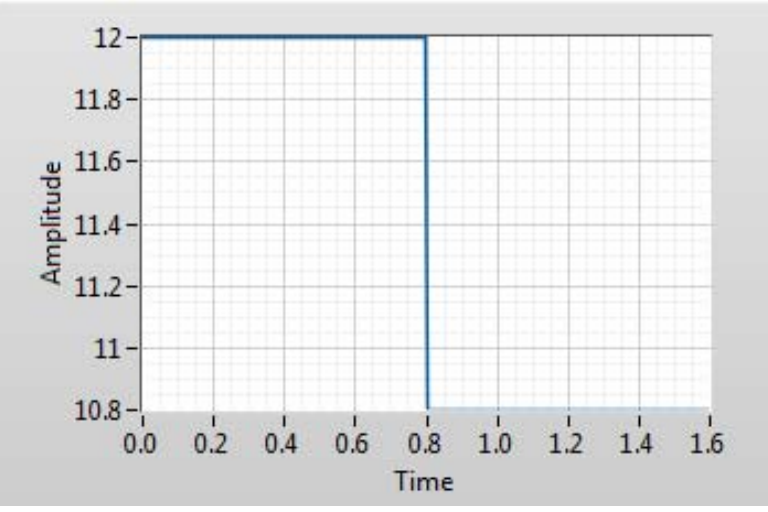

Fig. 10. Changing of the input voltage 


\section{CONCLusion}

In the current paper a modelling of a DC/DC boost converter is presented. A mathematical model in Matlab/Simulink and LabVIEW is realized. A comparison between two different software is realized. The obtained results from simulations confirm the appropriate work of the proposed mathematical model.

The depict model could be useful for multiple applications like personal electronics, automotive industry, photovoltaic systems and communication. In further researches the developed model could be apply for studying of photovoltaic systems for provide electric supply in micro and nanogrid.

\section{ACKNOWLEDGEMENT}

The paper is published with the support of the project No BG05M2OP001-2.009-0033 "Promotion of Contemporary Research Through Creation of Scientific and Innovative Environment to Encourage Young Researchers in Technical University - Sofia and The National Railway Infrastructure Company in The Field of Engineering Science and Technology Development" within the Intelligent Growth Science and Education Operational Programme co-funded by the European Structural and Investment Funds of the European Union.

\section{REFERENCES}

[1] R. H. G. Tan, L. Y. H. Hoo, "DC-DC Converter Modeling and Simulation using State Space Approach",
Energy Conversion (CENCON), 2015 IEEE Conference on, 2015.

[2] F. Nejabatkhah, S. Danyali, S. H. Hosseini, "Modeling and Control of a New Three-Input DC-DC Boost Converter for Hybrid PV/FC/Battery Power System", IEEE Transactions on Power Electronics, Vol. 27, Issue: 5, 2012, pp. $2309-2324$.

[3] R. W. Erickson, "DC-DC Power Converters", Wiley Encyclopedia of Electrical and Electronics Engineering, 2007.

[4] A.Khamis, M.N. Kamarudin, M. Y. Lada, M.S. Jamri, F. Hanafi, A. Nazmi, "Identification and Simulation of Dc-Dc Boost Converter for Charging Up PV Voltage for 24-Volts Battery", The Asia Pacific Symposium on Applied Electromagnetics and Mechanics, 2010.

[5] A. J. Forsyth and S. V. Mollov, "Modelling and control of DC-DC converters", Power Engineering Journal, vol. 12, Issue: 5, 1998, pp. 229 - 236.

[6] R. Priewasser, S. Marsili, "Modeling, Control, and Implementation of DC-DC Converters for Variable Frequency Operation", IEEE transactions on power electronics, Vol. 29, no. 1, January 2014, pp.287- 301.

[7] A. Shrivastava and B. H. Calhoun, "A DC-DC Converter Efficiency Model for System Level Analysis in Ultra Low Power Applications", J. Low Power Electron. Appl. 3, 2013, pp. 215-232.

[8] K. Bendaoud, J. Laassiri, S. Krit, L. El maimouni, "Design and simulation DC-DC Power Converters Buck and Boost for Mobile Applications using Matlab/Simulink", Engineering \& MIS (ICEMIS), International Conference on, 22-24 Sept. 2016.

[9] M. Sai Krishna Reddy, Ch. Kalyani, M. Uthra and D. Elangovan, "A Small Signal Analysis of DC-DC Boost Converter", Indian Journal of Science and Technology, Vol. 8(S2), January 2015, pp.1-6. 